\title{
Effect of Premelting on Conductivity of DNA-Lipid Films
}

\author{
A. Yu. Kasumov, ${ }^{1,2,3}$ S. Nakamae, ${ }^{4,5}, 6$ M. Cazayous, ${ }^{4,5}$ T. Kawasaki, ${ }^{7}$ and Y. Okahata ${ }^{7}$ \\ ${ }^{1}$ Laboratoire de Physique des Solides, UMR 8502 CNRS, Bâtiment 510, Université Paris-Sud, 91405 Orsay Cedex, France \\ ${ }^{2}$ Institute of Microelectronics Technology and High Purity Materials, Russian Academy of Sciences (RAS), 142432 Chernogolovka, \\ Moscow Region, Russia \\ ${ }^{3}$ RIKEN, Hirosawa 2-1, Wakō, Saitama 351-0198, Japan \\ ${ }^{4}$ Laboratoire de Physique du Solide, CNRS UPR 5, Ecole Supérieure de Physique et Chimie Industrielles de la Ville de Paris (ESPCI), \\ 75231 Paris Cedex, France \\ ${ }^{5}$ Laboratoire de Matériaux et Phénomène Quantiques (UMR 7162), UMR 7162, Université Denis-Diderot-Paris 7, 75251 Paris, France \\ ${ }^{6}$ Service de Physique de l'Etat Condensé, Commissariat à l'Énergie Atomique (CEA), Centre d'études de Saclay, \\ 91191 Gif-sur-Yvette, France \\ ${ }^{7}$ Department of Biomolecular Engineering, Tokyo Institute of Technology, 4259 Nagatsuda, Midori-ku, Yokohama 226-8501, Japan
}

Correspondence should be addressed to A. Yu. Kasumov, kasumov@lps.u-psud.fr

Received 17 November 2008; Accepted 30 January 2009

Recommended by Joseph Irudayaraj

We have measured temperature-dependent (between 20 and $80^{\circ} \mathrm{C}$ ) electrical conductivity and molecular structure (Raman spectroscopy) of DNA-lipid cast film. Our findings show that the conductivity is strongly influenced by premelting effects in the molecular structure starting near physiological temperatures $\left(\sim 40^{\circ} \mathrm{C}\right)$, prior to the global DNA denaturation.

Copyright ( $) 2009$ A. Yu. Kasumov et al. This is an open access article distributed under the Creative Commons Attribution License, which permits unrestricted use, distribution, and reproduction in any medium, provided the original work is properly cited.

Most measurements reported in the last decade on the DNA conductivity are conducted at room temperatures and below [1]. If DNA is to become exploitable in microelectronics applications, however, its performance must be reliable at temperatures slightly above the room temperature due to the inevitable heating of electronic components. It is generally agreed that natural DNA molecules undergo a denaturation process at $T_{d n}=70 \sim 80^{\circ} \mathrm{C}$. Above this temperature, the double-stranded molecular conformation is destroyed, and consequently, the electrical conductivity is lost $[2,3]$. According to numerous theoretical models $[4,5]$ even at physiological temperatures $\left(\sim 40^{\circ} \mathrm{C}\right)$, DNA experiences structural perturbations leading to local denaturations and/or "bubble-" type defect formations. The existence of "bubbles" $[6,7]$ as well as the temperature induced local perturbations at $T<T_{d n}$, termed "premelting," [812] has been confirmed experimentally, and the biological aspects of these local denaturations were discussed in a number of studies (see, e.g., [6]). Local deformations should cause breaking of a long-range order in the DNA structure (i.e., interruption of the parallel base-pair $(b p)$ stackings) similar to an order breaking in solid bodies due to the dislocation introduction. However, their influence on conductivity has not been properly addressed until now. In this work, we present the temperature-dependent conductivity and structural evolution monitored through Raman spectroscopy measured on the DNA-lipid cast film between physiological and denaturation temperatures. These DNA-lipid films were previously studied by Nakayama et al. [2], where disappearance of conductivity above the denaturation temperature was reported. We observed a substantial reduction in the DNA conductivity due to premelting effects starting at temperature as low as $40^{\circ} \mathrm{C}$, lending support to the theoretical inference on the importance of the long-range parallel $b p$ stacking in DNA for the electrical conduction.

Self-standing DNA-lipid cast films with thickness of about 60 microns were prepared according to the method described elsewhere [13]. Once the self-standing film is mechanically stretched, DNA molecules (natrual DNA, 2000 bp's each) are aligned along film's long axis with an average intermolecular distance of $41 \AA$. In previous investigations, Okahata et al. have verified the anisotropic 

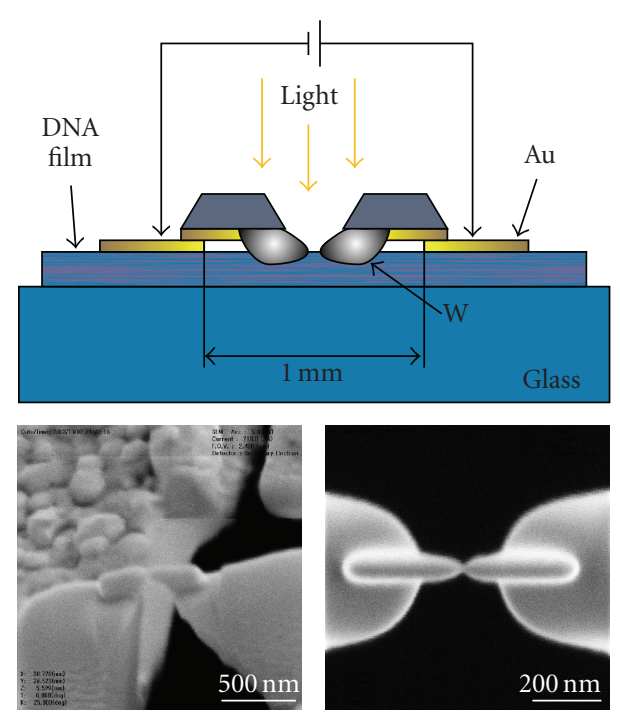

Figure 1: Conductivity measurement setup. One-micron-high tungsten (W) nanoelectrodes with a less than $5 \mathrm{~nm}$ separation were prepared by decomposing Tungsten hexacarbonyl by focused ion beam [15] on a silicon chip. The silicon chip was then pressed into the DNA-lipid film surface on which gold contacts had been predeposited. Below are SEM (left-side view) and FIB (right-top view) images of the tungsten nanoelectrodes.

conductivity through these films and concluded that the electrons are traveling through the molecules and not via the lipid matrix [13] (conductivity of these molecules was not suppressed by strong interaction with a solid surface as in [14]). For our conductivity measurements, a section of a film of about $5 \times 0.5 \mathrm{~cm}^{2}$ was placed on a glass plate. The detailed description of measurement apparatus is given in Figure 1. The measurements were performed in Hewlett-Packard measurement systems in a dark box at temperatures of $30-150^{\circ} \mathrm{C}$ and with or without illumination (the temperature checked by melting points of $\mathrm{Ga}$ and $\mathrm{In}$ ). The leak current through the contacts was less than $1 \mathrm{nA}$ in the measurement range of $\pm 3 \mathrm{~V}$ and for temperatures between 25 and $80^{\circ} \mathrm{C}$, irrespective of illumination. Indentation created by the electrodes in soft insulators, such as resist or teflon, leads only to a reduction of the leak current due to an increase in the distance between electrodes. Similar increase is expected in the DNA film, while the total current (I) at $3 \mathrm{~V}$ reaches $1 \mu \mathrm{A}$ and larger. Once heating the film to $150^{\circ} \mathrm{C}$, I again decreases down to $\sim 1 \mathrm{nA}$.

With illumination of $3 \mathrm{~mW} / \mathrm{cm}^{2}$ (Halogen photo-optic lamp, unfiltered, and unpolarized), the overall conductivity and the maximal current $\left(\mathrm{I}_{\max }=\mathrm{I}(-3 \mathrm{~V})\right)$ through the DNA-film start to diminish at about $40^{\circ} \mathrm{C}$ (Figure 2(a)). The largest change is observed between 35 and $45^{\circ} \mathrm{C}$ (Figure 2(b)), where $\mathrm{I}_{\max }$ is reduced by more than $70 \%$. The stability of the temperature was $\pm 0.5^{\circ} \mathrm{C}$ during I$\mathrm{V}$ characteristic measurements. When measurements are conducted in dark, the conductivity is 5 times smaller at $35^{\circ} \mathrm{C}$ and the temperature-dependent reduction of $\mathrm{I}_{\max }$ is limited to $20 \%$ (not shown). These temperature-induced changes in the conductivity are entirely reversible upon thermal

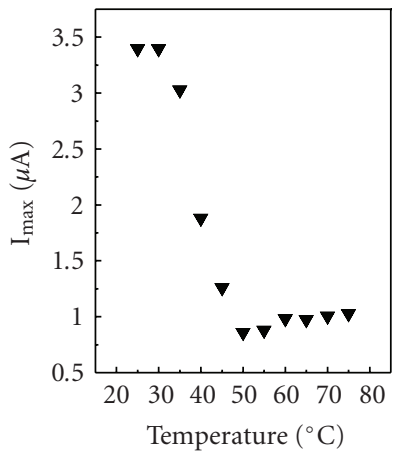

(a)

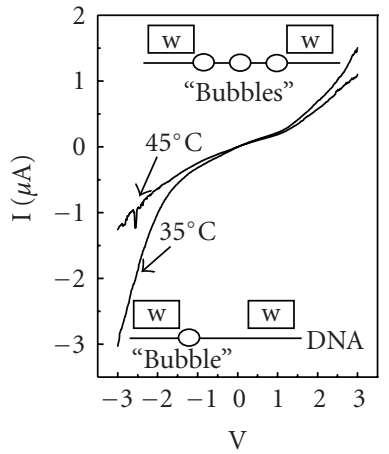

(b)

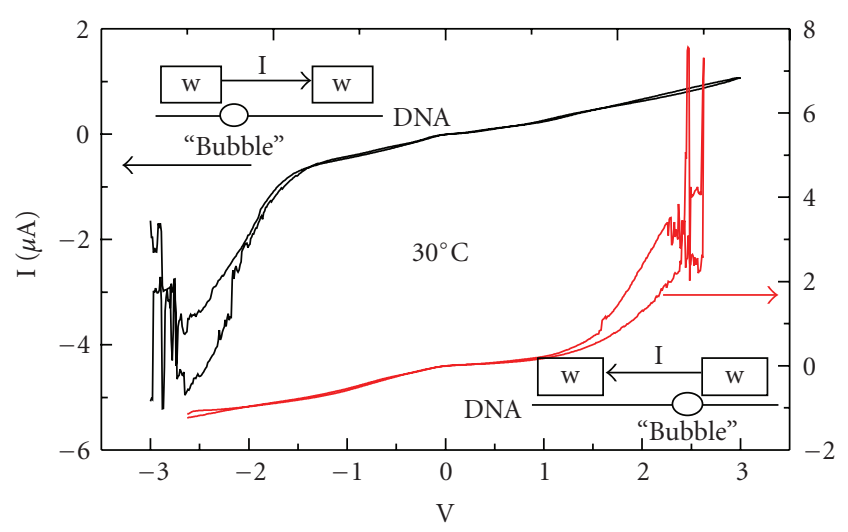

(c)

FIGURE 2: Temperature-dependent conductivity measurements under luminosity: (a) temperature dependence of $I_{\max }$, (b) $I-V$ characteristics of the DNA film at 35 and $45^{\circ} \mathrm{C}$. The insets show the increasing number of bubbles with a temperature, (c) irreversible $\mathrm{I}-\mathrm{V}$ characteristics $\left(\right.$ at $30^{\circ} \mathrm{C}$ ) of the DNA film which had been subjected to a high bias voltage at $80^{\circ} \mathrm{C}$ with opposing polarities. The insets show the assumed schematics of the bubble type defect movements inside the DNA molecules at $80^{\circ} \mathrm{C}$.

cycling provided that the DNA-film is not subjected to a high voltage bias $( \pm 3 \mathrm{~V})$ at the highest temperature $\left(80^{\circ} \mathrm{C}\right)$. The most probable reason for the conductivity reduction is the creation of local defects (premelting), as indicated by Raman spectrum evolution (described below), analogous to that of local dislocations in a solid body during hightemperature annealing. In the case of a solid body, local dislocations can physically migrate at elevated temperatures and stop close to grain or phase boundaries [16]. Therefore, local defects in DNA can be expected to also advance close to the tungsten nanoelectrodes, inducing irreversible changes in the molecule-metal contact characteristics [17]. We indeed observe such irreversibility in conductivity when the sample was maintained at $80^{\circ} \mathrm{C}$ for $10-15$ minutes with the maximum voltage $(3 \mathrm{~V})$ of a chosen polarity. After cooling the sample back down to $30^{\circ} \mathrm{C}, \mathrm{I}(\mathrm{V})$ instability is observed on the positive branch (Figure 2(c)). When the sample was reheated to $80^{\circ} \mathrm{C}$ with $\mathrm{V}$ of the opposite sign, the instability appears on the negative branch of $\mathrm{I}(\mathrm{V})$ curve after cooling to $30^{\circ} \mathrm{C}$. We observed such behavior up to 4 cycles of measurements. 


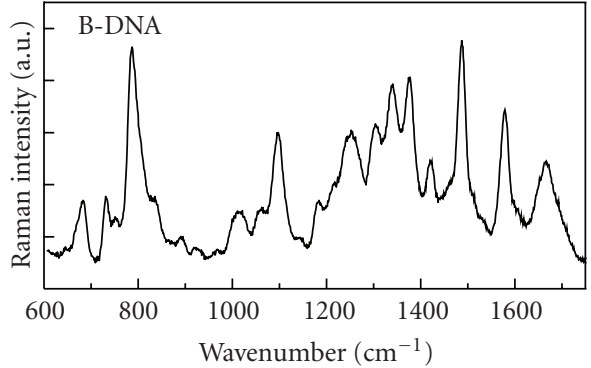

(a)

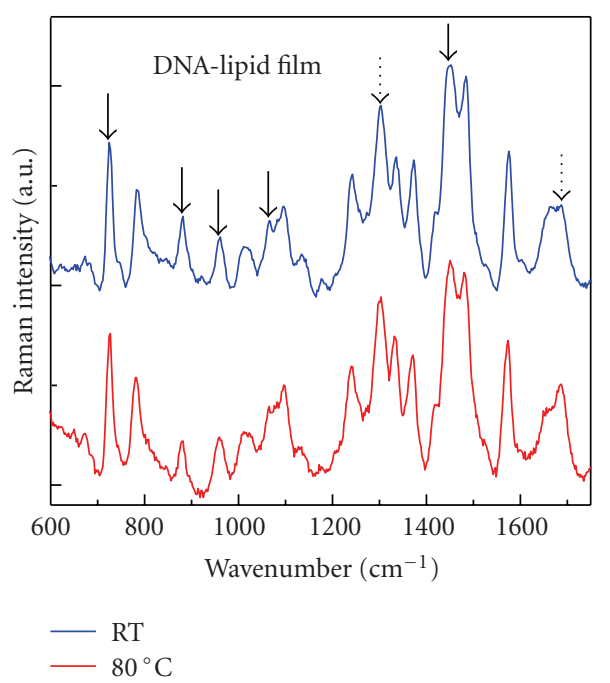

(b)

Figure 3: Raman spectra of natural B-DNA (top) and the DNAlipid complex at room temperature and at $80^{\circ} \mathrm{C}$. The solid arrows indicate the Raman peaks unique to the lipid complex. The dotted arrows indicated the peaks that contain contributions from both DNA molecules and the lipid complex. For detailed annotation of individual Raman bands, the readers are kindly asked to refer to literature, for example, $[8,18,19]$. The Raman bands corresponding to the lipid-complex did not show heating-induced shifting while certain DNA bands moved to lower wave numbers. The DNA $\mathrm{PO}^{-}$ symmetric stretching mode remains at $1092 \mathrm{~cm}^{-1}$ throughout the measurements, indicating that the DNA molecules remains in their $\mathrm{B}$-form without a significant change in the relative humidity around the molecules.

In order to associate the conductivity changes with DNA structural modifications, we have tracked the structural evolution of DNA molecules by Raman spectroscopy. The $514.5 \mathrm{~nm}$ excitation line of an $\mathrm{Ar}^{+}-\mathrm{Kr}^{+}$laser was focused on the samples through a $50 \mathrm{x}$ magnification objective lens with a radiation power at source of $10 \mathrm{~mW}$. The scattered light was analyzed using a Jobin-Yvon triple grating spectrometer in the confocal configuration. The effective spectral resolution was less than $1 \mathrm{~cm}^{-1}$. Raman spectra were taken in the $10-$ $80^{\circ} \mathrm{C}$ temperature range on several films from the same batch as the conductivity measurements. The spectra of DNA-lipid complex taken at room temperature and at $80^{\circ} \mathrm{C}$ as well as that of natural B-DNA (also taken in our lab) are compared in Figure 3. Temperature-dependent Raman spectra of the
DNA-lipid complex films showed certain notable differences from those observed in DNA molecules in aqueous solution. First, a cooperative melting of double-stranded DNA was not observed even at $80^{\circ} \mathrm{C}$, whereas the premelting effects in $10-65^{\circ} \mathrm{C}$ range were clearly present. We also remarked that nearly all vibrational modes exhibit a reversible temperature dependency during premelting after the heating and the subsequent cooling of the films (not shown). Structural rigidity of molecules imposed by the lipid intercalation may explain these differences. It should also be noted that the hypochromic effect [12] was not observed with exception of $1680 \mathrm{~cm}^{-1}$ marker due to the progressive change in the background luminescence of the film. Therefore, we have used the heating-induced shifts in Raman peaks to track the premelting effects in DNA molecules. These peaks are sensitive to (i) backbone and deoxynucleoside conformations, (ii) interbase hydrogen bonding, and (iii) base stacking effect.

(i) The broad peak at $780 \mathrm{~cm}^{-1}$ contains contributions from $\mathrm{dC}, \mathrm{dT}$, and the $5^{\prime} \mathrm{C}-\mathrm{O}-\mathrm{P}-\mathrm{O}-\mathrm{C}^{\prime}$ backbone stretching. The peak frequency shifts down from 781 to $776 \mathrm{~cm}^{-1}$ ) starting around $45^{\circ} \mathrm{C}$ until nearly $70^{\circ} \mathrm{C}$ (see Figure 4(a)). The peak located at $840 \mathrm{~cm}^{-1}$ originates from the $5^{\prime} \mathrm{C}-\mathrm{O}-\mathrm{P}-\mathrm{O}-\mathrm{C} 3^{\prime}$ phosphodiester backbone movements and can be used as a quantitative measure of the ordered phosphodiester. This peak decreases in intensity and disappears into the background. The $746 \mathrm{~cm}^{-1}$ peak is the vibrational marker of $\mathrm{C} 2^{2}$-endo/anti conformation of $\mathrm{dT}$. This peak broadens and shifts strongly to lower frequency indicating the extended distribution of conformations at higher temperature (Figure $4(\mathrm{~b})$ ). The onset of this movement is $55^{\circ} \mathrm{C}$ and continues to shift toward lower frequency up to $80^{\circ} \mathrm{C}$.

(ii) The bands at 1482 and $1573 \mathrm{~cm}^{-1}$ correspond to ring stretching vibrations of purine imidazole ring and are sensitive to hydrogen bonding. The both peaks shift to lower frequencies by 1 and $3 \mathrm{~cm}^{-1}$, respectively, between 35 and $40^{\circ} \mathrm{C}$, and stabilize for temperature above $65^{\circ} \mathrm{C}$ (Figure $4(\mathrm{c})$ ). These shifts are the signature of the thermoinstability of base pairing. Moreover, the $3 \mathrm{~cm}^{-1}$ shiftdown of the Raman peaks between $1200-1400 \mathrm{~cm}^{-1}$ is associated with elimination of hydrogen bonding between bases (Figure 4(d)).

(iii) The intensity evolution of three peaks located at 1658,1668 , and $1682 \mathrm{~cm}^{-1}$ (inset of Figure $4(\mathrm{~b})$ ) are normally attributed to the base stacking effects related to carbonyl stretching vibrations coupled to ring stretching vibration (mostly dT) [19]. The Raman peak at $1682 \mathrm{~cm}^{-1}$ of the DNA-lipid film is, however, considerably more intense than in a typical B-DNA (see Figure 3), suggesting that contribution from the lipid complex cannot be ignored. Hence, we cannot conclude the hypochromicity observed here to the effect of DNA premelting without further investigation. 


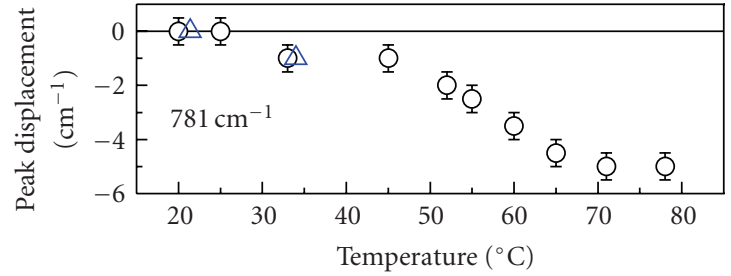

(a)

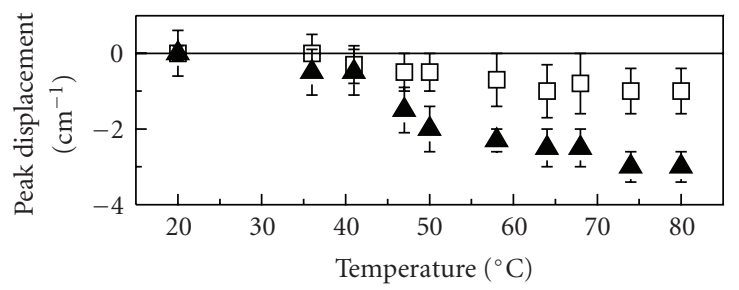

A $1573 \mathrm{~cm}^{-1}$

ㅁ $1482 \mathrm{~cm}^{-1}$

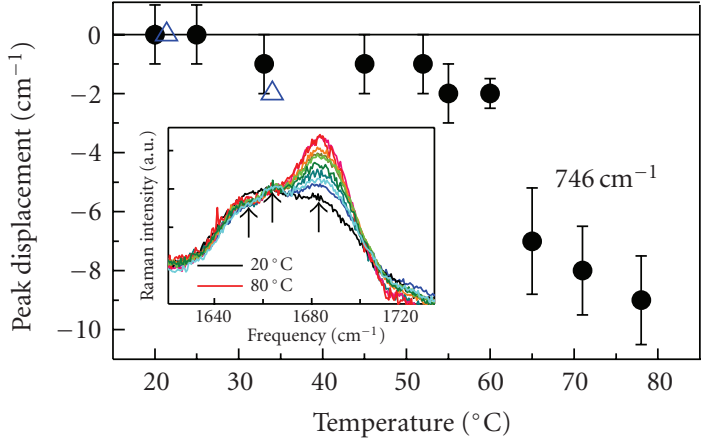

(b)

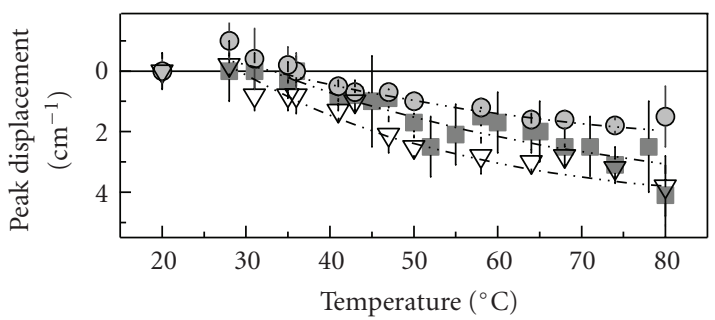

- $1238 \mathrm{~cm}^{-1}$ O $1333 \mathrm{~cm}^{-1}$ $\nabla 1370 \mathrm{~cm}^{-1}$

(d)

Figure 4: Temperature-dependent premelting effect in Raman frequencies of (a) the admixture of complex vibration of the B-DNA phosphodiester backbone conformation and thymine and cytosine ring modes [18], (b) dT C2' -endo sugar pucker and anti glycosyl torsion mode [8], and (c) dG and dA ring stretching vibrations sensitive to hydrogen bonding [18, 19] as well as dT [10]. The bands shift toward lower frequencies starting near $35^{\circ} \mathrm{C}$ and the movement attenuates for $65^{\circ} \mathrm{C}$ and higher for phosphodiester geometry and deoxyribose hydrogen bond vibrations. The onset of premelting effect at $746 \mathrm{~cm}^{-1}$ occurs near $50^{\circ} \mathrm{C}$. (d) Interbase hydrogen bonding. The bands returns to their original position once the film is cooled back down to room temperature (see blue triangles in panels (a) and (b)). inset b: The intensity change near $1660-1680 \mathrm{~cm}^{-1}$ is observable from $35^{\circ} \mathrm{C}$ and higher with no sign of attenuation. The spectra are normalized to the intensity values at $1664 \mathrm{~cm}^{-1}$ in order to show the relative intensity change among three bands (indicated by 3 arrows). The continued enhancement of $1680 \mathrm{~cm}^{-1}$ from room temperature to $80^{\circ} \mathrm{C}$ is clearly observed. The bands at 1664 and $1650 \mathrm{~cm}^{-1}$ are indistinguishable at $20^{\circ} \mathrm{C}($ thick line), and separate themselves into two distinct peaks at 1664 and $1648 \mathrm{~cm}^{-1}$ at $80^{\circ} \mathrm{C}$ (thin line).

As described before, the premelting effects observed in DNA Raman signatures coincide with the temperature dependence of electrical conductivity measured in these films. Local destruction of double-stranded DNA conformation caused by premelting effects is most simply described as a "bubble" creation. The formation of such bubbles, and, more importantly, its movement within the molecule is just like a dislocation loop moving in a metal microwire subjected to a high current density [20]. The insets in Figure 2(c) will help understand the observed changes in electrical conductivity (Figure 2). Probably, in the presence of defects, the potential barrier in the vicinity of the molecule-metal contact decreases. This barrier reduction is a known effect in metal-semiconductor microcontacts near a dislocation [21] (the reduction is more dramatical under illumination), and electromigration (the physical displacement of defects under an applied electrical current) is also well known [22]. In electromigration, the direction of dislocation movement can be switched by changing the current direction. To estimate the pressure on a "bubble" by an electron wind, the current density in a DNA molecule must be known. Emerging consensus states that DNA molecules longer than $10 \mathrm{~nm}$ combined with bad electric contacts become insulating [23]. Therefore, no more than 10 molecules at the film surface should be electrically active in our measurements. Taking $2 \mathrm{~nm}$ as the DNA diameter, the corresponding current density would be as high as $10^{7} \mathrm{~A} / \mathrm{cm}^{2}$, comparable to a current density required to drag a dislocation in a metal microwire [20]. One can estimate the applied force on a bubble, $F_{b}$, using the equation for a dislocation in a metal [24]: $F_{b}=j m^{*} V f S_{b} / e$, where $j$ is the current density, $m^{*}$ and $V_{f}$ are the effective mass and Fermi velocity of the electrons injected in DNAs from the tungsten electrods [25], $S_{b}$ is the scattering cross-section of the electrons by a bubble, and $e$ is the electron charge. The applied force is about $1 \mathrm{pN}$ (with $m \sim 10^{-30} \mathrm{~kg}$ and $V_{f} \sim 10^{6} \mathrm{~m} / \mathrm{s}$ in $\mathrm{W}[26]$, $S_{b} \sim 1 \mathrm{~nm}^{2}$ for a small bubble) which is enough to deform a DNA molecule [6]. The number of bubbles increases with temperature [5], and it decreases the conductivity of DNAs (Figure 2(b)) and makes I-V characteristics more symmetrical (probably due to symmetrical molecule-metal contacts, see insets in Figure 2(b)). 
In summary, our measurements demonstrate that the electrical conduction in DNA can be compromised under moderate heating above room temperature due to local disruptions in the long-range B-DNA structure. Furthermore, displacement of defects along molecules could explain why the structural transformation, as probed by Raman spectroscopy, is a reversible process while the electrical conductivity is not.

\section{Acknowledgments}

We thank D. Klinov, H. Bouchiat, S. Gueron, A. Braslau, and K. Tsukagoshi for useful discussions, and acknowledge the financial support by the Russian Foundation for Basic Research and ANR Quantadn.

\section{References}

[1] M. Di Ventra and M. Zwolak, "DNA electronics," in Encyclopedia of Nanoscience and Nanotechnology, H. S. Nalwa, Ed., vol. 2, p. 475, American Scientific, Stevenson Ranch, Calif, USA, 2004.

[2] H. Nakayama, H. Ohno, and Y. Okahata, "Intramolecular electron conduction along DNA strands and their temperature dependency in a DNA-aligned cast film," Chemical Communications, no. 22, pp. 2300-2301, 2001.

[3] S. M. Iqbal, G. Balasundaram, S. Ghosh, D. E. Bergstrom, and R. Bashir, "Direct current electrical characterization of dsDNA in nanogap junctions," Applied Physics Letters, vol. 86, no. 15, Article ID 153901, 3 pages, 2005.

[4] T. Hwa, E. Marinari, K. Sneppen, and L.-H. Tang, "Localization of denaturation bubbles in random DNA sequences," Proceedings of the National Academy of Sciences of the United States of America, vol. 100, no. 8, pp. 4411-4416, 2003.

[5] M. Peyrard, "Melting the double helix," Nature Physics, vol. 2, no. 1, pp. 13-14, 2006.

[6] T. R. Strick, V. Croquette, and D. Bensimon, "Homologous pairing in stretched supercoiled DNA," Proceedings of the National Academy of Sciences of the United States of America, vol. 95, no. 18, pp. 10579-10583, 1998.

[7] K. A. Schallhorn, K. O. Freedman, J. M. Moore, J. Lin, and P. C. $\mathrm{Ke}$, "Single-molecule DNA flexibility in the presence of basepair mismatch," Applied Physics Letters, vol. 87, no. 3, Article ID 033901, 3 pages, 2005.

[8] L. Movileanu, J. M. Benevides, and G. J. Thomas Jr., "Determination of base and backbone contributions to the thermodynamics of premelting and melting transitions in $B$ DNA," Nucleic Acids Research, vol. 30, no. 17, pp. 3767-3777, 2002.

[9] L. Movileanu, J. M. Benevides, and G. J. Thomas Jr., “Temperature dependence of the Raman spectrum of DNA-part I: Raman signatures of premelting and melting transitions of Poly (dA-dT) · poly (dA-dT)," Journal of Raman Spectroscopy, vol. 30, no. 8, pp. 637-649, 1999.

[10] I. Mukerji and A. P. Williams, "UV resonance Raman and circular dichroism studies of a DNA duplex containing an $\mathrm{A}_{3} \mathrm{~T}_{3}$ tract: evidence for a premelting transition and threecentered H-bonds," Biochemistry, vol. 41, no. 1, pp. 69-77, 2002.

[11] V. Carrier and R. Savoie, "Raman spectroscopic study of the conformation and melting of poly $(\mathrm{dG}) \cdot \operatorname{poly}(\mathrm{dC})$ and poly $(\mathrm{dG}-\mathrm{dC}) \cdot \operatorname{poly}(\mathrm{dG}-\mathrm{dC})$ in aqueous solution," Journal of Solution Chemistry, vol. 29, no. 10, pp. 1027-1038, 2000.

[12] B. L. Tomlinson and W. L. Peticolas, "Conformational dependence of Raman scattering intensities in polyadenylic acid," Journal of Chemical Physics, vol. 52, no. 4, pp. 2154-2156, 1970.

[13] Y. Okahata, T. Kobayashi, H. Nakayama, and K. Tanaka, "DNA-aligned cast film and its anisotropic electron conductivity," Supramolecular Science, vol. 5, no. 3-4, pp. 317-320, 1998.

[14] A. Yu. Kasumov, D. V. Klinov, P.-E. Roche, S. Guéron, and H. Bouchiat, "Thickness and low-temperature conductivity of DNA molecules," Applied Physics Letters, vol. 84, no. 6, pp. 1007-1009, 2004.

[15] A. Yu. Kasumov, K. Tsukagoshi, M. Kawamura, et al., "Proximity effect in a superconductor-metallofullerenesuperconductor molecular junction," Physical Review B, vol. 72, no. 3, Article ID 033414, 4 pages, 2005.

[16] J. Friedel, Dislocations, Pergamon Press, Oxford, UK, 1964.

[17] A. Grigoriev, J. Sköldberg, G. Wendin, and Ž. Crljen, "Critical roles of metal-molecule contacts in electron transport through molecular-wire junctions," Physical Review B, vol. 74, no. 4, Article ID 045401, 16 pages, 2006.

[18] H. Deng, V. A. Bloomfield, J. M. Benevides, and G. J. Thomas Jr., "Dependence of the raman signature of genomic B-DNA on nucleotide base sequence," Biopolymers, vol. 50, no. 6, pp. 656-666, 1999.

[19] J. G. Duguid, V. A. Bloomfield, J. M. Benevides, and G. J. Thomas Jr., "DNA melting investigated by differential scanning calorimetry and Raman spectroscopy," Biophysical Journal, vol. 71, no. 6, pp. 3350-3360, 1996.

[20] E. E. Vdovin and A. Yu. Kasumov, "Direct observation of electrotransport of dislocations in a metal," Soviet Physics of Solid State, vol. 30, p. 180, 1988.

[21] H. F. Matare, Defect Electronics in Semiconductors, John Wiley \& Sons, New York, NY, USA, 1971.

[22] K. N. Tu, "Recent advances on electromigration in very-largescale-integration of interconnects," Journal of Applied Physics, vol. 94, no. 9, pp. 5451-5473, 2003.

[23] A. J. Storm, J. van Noort, S. de Vries, and C. Dekker, "Insulating behavior for DNA molecules between nanoelectrodes at the $100 \mathrm{~nm}$ length scale," Applied Physics Letters, vol. 79, no. 23, pp. 3881-3883, 2001.

[24] V. B. Fiks, "Interaction of conduction electrons with single dislocations in metals," Soviet Physics JETP, vol. 53, p. 1209, 1981.

[25] M. Zvolak and M. Di Ventra, "DNA spintronics," Applied Physics Letters, vol. 81, no. 5, pp. 925-927, 2002.

[26] N. Ashcroft and N. D. Mermin, Solid State Physics, Holt, Rinehart and Winston, New York, NY, USA, 1976. 

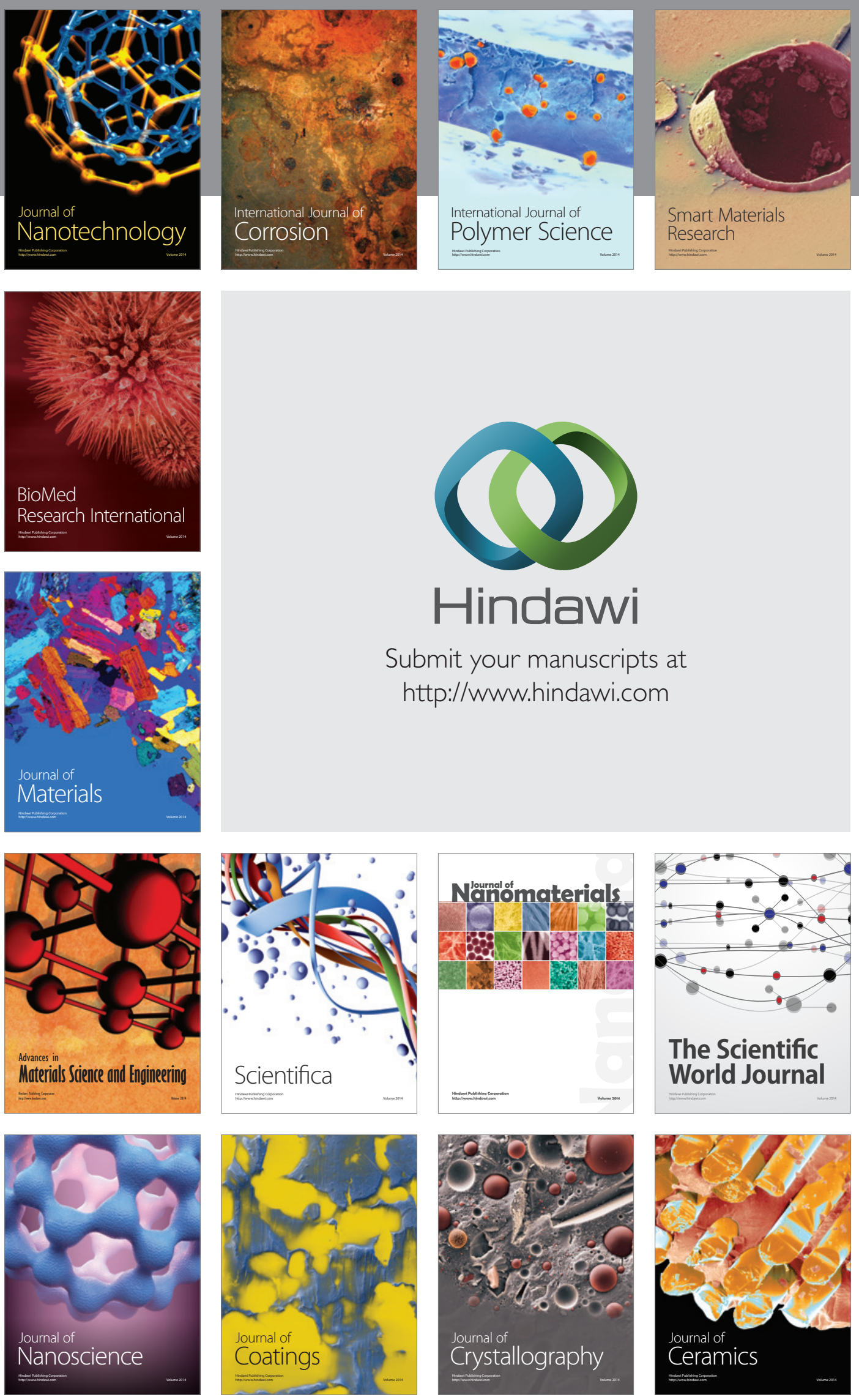

The Scientific World Journal

Submit your manuscripts at

http://www.hindawi.com

\section{World Journal}

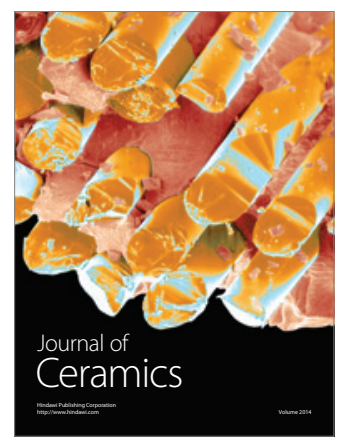

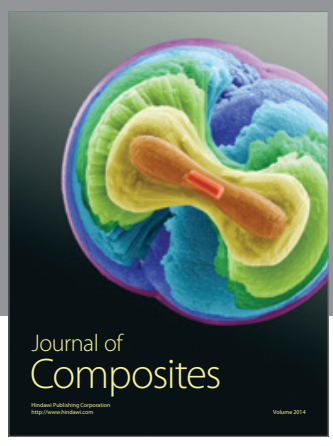
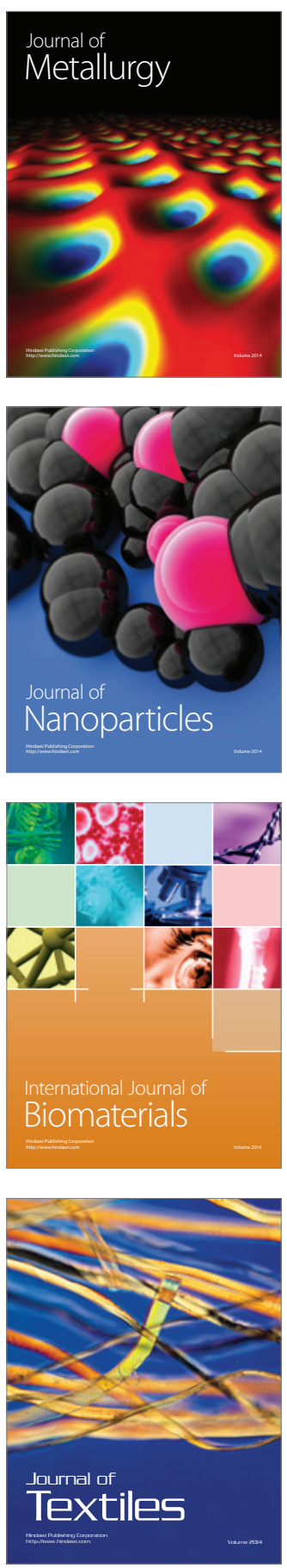